\title{
High Risk Infants Follow-Up: A Case Study in Iran
}

\author{
Mohammad Heidarzadeh, ${ }^{1}$ Behzad Jodeiry, ${ }^{1}$ Mohammad Baqer Hosseini, ${ }^{1}$ Kayvan Mirnia, ${ }^{1}$ \\ Forouzan Akrami, ${ }^{2}$ Abbas Habbibollahi, ${ }^{3}$ Sara Moazzen, ${ }^{4}$ and Saeed Dastgiri ${ }^{4}$ \\ ${ }^{1}$ Pediatric Health Research Center, Tabriz University of Medical Sciences, Tabriz 5166615739, Iran \\ ${ }^{2}$ Medical Ethics and Law Research Center, Shahid Beheshti University of Medical Sciences, Tehran, Iran \\ ${ }^{3}$ Deputy of Public Health, Ministry of Health and Medical Education, Tehran, Iran \\ ${ }^{4}$ Tabriz Health Services Management Research Centre, Tabriz University of Medical Sciences, Tabriz 5166615739, Iran
}

Correspondence should be addressed to Saeed Dastgiri; dastgiris@tbzmed.ac.ir

Received 25 April 2015; Revised 19 May 2015; Accepted 20 May 2015

Academic Editor: Tonse N. K. Raju

Copyright (c) 2015 Mohammad Heidarzadeh et al. This is an open access article distributed under the Creative Commons Attribution License, which permits unrestricted use, distribution, and reproduction in any medium, provided the original work is properly cited.

\begin{abstract}
Background. A follow-up program for high risk infants was initiated in Alzahra Maternity Hospital in Tabriz city, Iran, in 2013. The aim of this paper is to give a brief report of the program. Material and Methods. Two groups of high risk neonates were studied. The first group comprising 509 infants received services in Alzahra Maternity Hospital implemented by the follow-up program. This included a full package for family to look after high risk infant and periodic clinical evaluation at two and four weeks after birth and then two, three, four, five, and six months later again. The second group including 131 infants in Taleqani Maternity Hospital received routine services after birth with no specific follow-up care. Results. Some anthropometric indices showed a significant improvement in the intervention hospital compared to control group. These included the following: head circumference at first and second months; weight in the first, fourth, fifth, and sixth months; and height in sixth month only. Clinical evaluation of infants showed an improvement for some of the medical conditions. Conclusion. Follow-up care program for a minimum of six months after discharge from maternity hospitals may help to avoid adverse and life threatening consequences in high risk infants.
\end{abstract}

\section{Introduction}

According to Barker's theory, certain risk exposures few months before pregnancy, during pregnancy, and in early childhood might have a role in the occurrence of some disorders in adulthood [1]. It is, therefore, essential to monitor the medical status of neonates, particularly those at certain risks, to keep them healthy and to avoid adverse consequences later in the life. Some studies showed that for preventing irreversible consequences in high risk infants, they need to be specifically looked after by a team of experts with various skills [2-12]. The definition of high risk infants and the approaches suggested for the follow-up of high risk children are discussed in detail elsewhere [12]. Implementation of any follow-up program for high risk infants would largely depend on existing facilities, family circumstances, and infant status. [13-18].

A follow-up program for high risk infants was initiated in Alzahra Maternity Hospital in Tabriz city of Iran in 2013 [19].
The main objective of the program was to create a pilot model for possible implementation of follow-up care for high risk infants across the country. The aim of the current paper is to give a brief report of this program.

\section{Material and Methods}

This study was carried out in Tabriz city. The city is one of the three major cities in Iran located in the northwest of Iran, a cold climate zone, with a total population of 1,398,060 in 2012 and an average annual population growth rate of 0.8 percent.

High risk infant was mainly defined based on the birth weight (less than 1500 grams) and gestational age (less than 32 weeks). If an infant did not, however, have those criteria, other medical conditions (i.e., major surgery in the neonatal period, seizures or fits, and serious illnesses such as meningitis or congenital malformation) were considered for risk assessment at birth/soon after. Full details of the high risk conditions can be found elsewhere [20,21]. 
Two groups of high risk neonates were studied. The first group comprising 509 infants (282 boys and 227 girls) received services in Alzahra Maternity Hospital implemented by the follow-up program. This included a full package for family/mothers to train them to look after high risk infant and periodic clinical evaluation by fully equipped/trained medical staff at two and four weeks after birth and then two, three, four, five, and six months later again. At those time points, the pediatric nurse of the program called the family (mainly mother) to bring the child for clinical follow-up. At this regular medical program, every infant was assessed for cardiac problems, lung diseases, gastroesophageal reflux, anemia and nutritional assessment (mainly based on weight, height, and head circumference), immunization (according to the country regular plan), hypothyroidism, osteopenia, nephrocalcinosis, renal tabular acidosis, Developmental Dislocation of Hip (DDH), intraventricular hemorrhage, neurodevelopmental assessment (using Ages and Stages Questionnaire at the second, fourth, and sixth months), retinopathy, auditory assessment, a comprehensive psychological assessment and mental health (including autism, etc.), sleep disorders (using a standardized questionnaire), oral health assessment, and anthropometric indices (including weight, height, and head circumference). Bronchopulmonary Dysplasia (BPD) is routinely fully managed during the hospital stay for every high risk infant. After discharge, a detailed followup program is organized beginning from the fourth year onward.

The second group including 131 infants ( 63 boys and 68 girls) in Taleqani Maternity Hospital received routine services after birth with no specific/regular follow-up or any specific nurse for this. They were medically assessed at the same time points and at the same hospital to compare them with the status of high risk infants in the first group. Infants diagnosed, as high risk infants, in two maternity centers (Alzahra, as pilot, and Taleqani, as control hospitals) entered the followup program. These hospitals routinely provide obstetric and gynecological services in the study population under the Tabriz University of Medical Sciences. Those hospitals are both public maternity facilities in similar social/economic areas. They are located in two different places in the city covering the population in two various zones in the city. Confounding factors were considered in both groups for the purpose of data analysis. Those factors included gender and risk status (based on birth weight and gestational age).

We also assessed the attitude and practice of staff and families towards the program using a questionnaire and interview and filling a check list while they are doing the job.

For the data analysis, we calculated 95\% confidence interval for statistical indicators.

The study obtained ethics approval from the committee of ethics in Tabriz University of Medical Sciences. All personal and identity information were kept confidential. Medical staff and families were asked whether or not they are willing to participate in the study and were told that they are free to leave for any reason at any time.

\section{Results}

Of those high risk infants eligible for follow-up care in Alzahra Hospital, 33 percent (95\% confidence intervals: $28.0-$ 37.9) refused, even after they were called for three times, to enter the follow-up program where 84 percent $(95 \%$ confidence intervals: 76.6-91.5) of control families with high risk infants did not participate in the hospital for followup services. In both groups, those refusing families either preferred to get follow-up services from private doctors and clinics or never got follow-up care at all over the study period.

We compared the improvement of clinical and anthropometric indices in Alzahra and Taleqani Hospital to assess the effectiveness of this program. Some anthropometric indices showed a significant improvement in the intervention hospital compared to control group over the follow-up period. These included the following: head circumference at first and second months; weight in the first, fourth, fifth, and sixth months; and height in sixth month only (Table 1). There was an overall improvement for the mean of head circumference, height, and weight between second week and sixth month (follow-up period) in Alzahra Hospital compared to control hospital. This change was statistically significant for mean height only.

Table 2 presents the proportion of high risk infants admitted to the outpatient clinics in both hospitals for assessment for various medical conditions and reasons. Clinical evaluation of infants in two hospitals broadly showed an increase in the screening for many of medical conditions. For instance, 21.6 percent of gastroesophageal reflux cases (95\% confidence intervals: 18.0-25.2) were found and then medically managed in Alzahra Hospital where the same figure was 7.6 percent (95\% confidence intervals: 3.1-12.2) in control hospital. In contrast, in some instances there was a better screening in control hospital: 14.5 percent of cardiac problems (95\% confidence intervals: 8.5-20.6) were diagnosed in control hospital while it was 2.2 percent only in the first group (95\% confidence intervals: 0.81-3.4).

\section{Discussion}

In this paper, we briefly reported a follow-up care program for high risk infants in Tabriz city of Iran. We showed that the program was seemingly effective in finding and managing some of the medical conditions in neonates over the sixmonth follow-up. Similar findings were reported before from various countries [22-28]. However, for implementing the program at regional or national levels, some technical, logistic, and financial aspects should be considered including the following:

(a) Before the program begins, it is essential to appoint a neonatologist (where unavailable, a general pediatrician) and a trained pediatric nurse/midwife as the focal points for the program in every hospital qualified for starting the follow-up care program for high risk infants. The program nurse/midwife will 


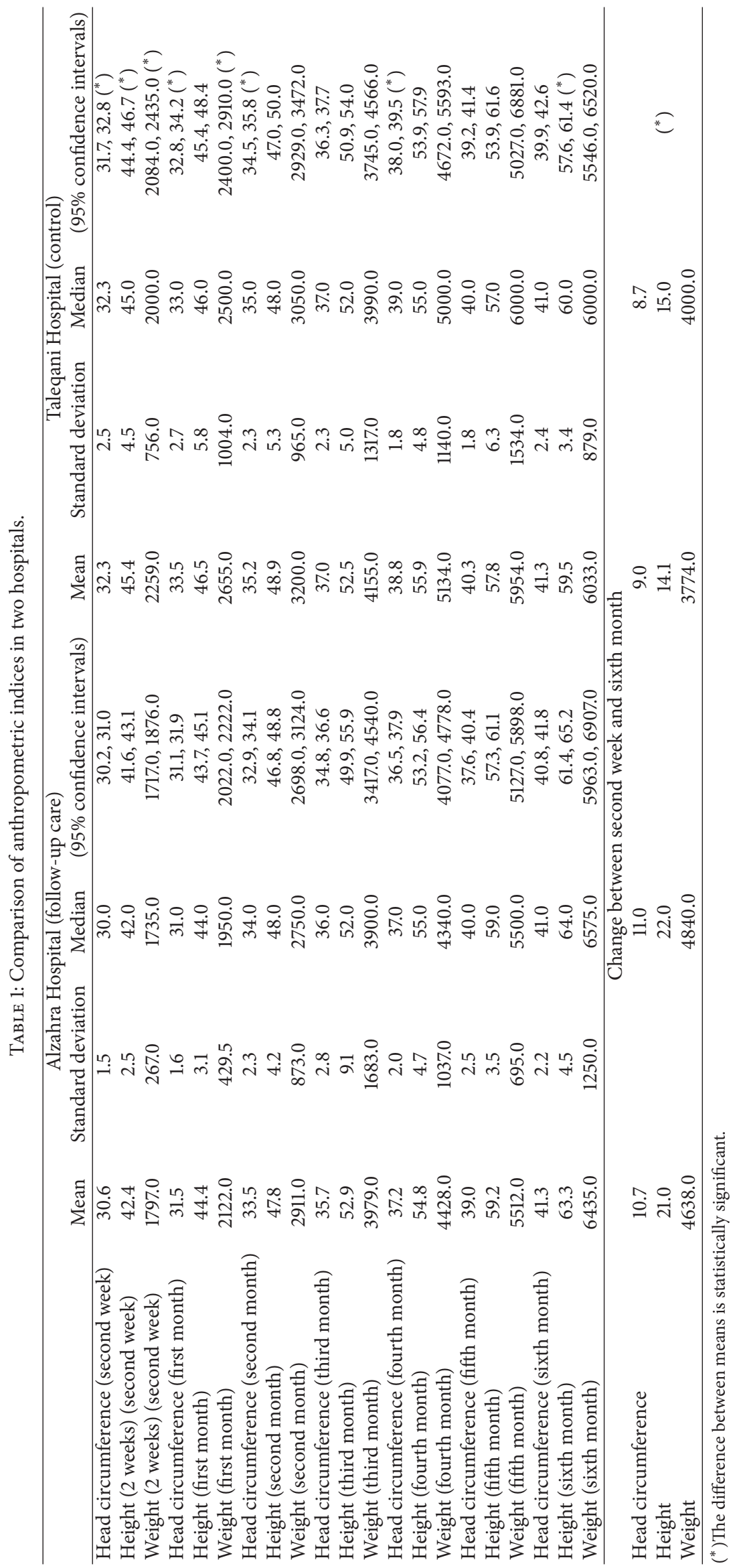


TABLE 2: Proportion of high risk infants clinically managed over the follow-up period.

\begin{tabular}{|c|c|c|c|c|}
\hline & \multicolumn{2}{|c|}{ Alzahra Hospital (follow-up care) $(n=509)$} & \multicolumn{2}{|c|}{ Taleqani Hospital (control) $(n=131)$} \\
\hline & Admitted/managed & Confidence intervals & Admitted/managed & Confidence intervals \\
\hline & $\%$ & $(95 \%)$ & & \\
\hline Cardiac problems & 2.2 & $0.8,3.4$ & 14.5 & $8.5,20.6\left(^{*}\right)$ \\
\hline Blood pressure & 0 & $0.0,0.0$ & 0 & $0.0,0.0$ \\
\hline Gastroesophageal reflux & 21.6 & $18.0,25.2$ & 7.6 & $3.1,12.2\left(^{*}\right)$ \\
\hline $\begin{array}{l}\text { Bronchopulmonary } \\
\text { dysplasia }\end{array}$ & 0.0 & $0.0,0.0$ & 0.0 & $0.0,0.0$ \\
\hline $\begin{array}{l}\text { Respiratory syncytial } \\
\text { virus }\end{array}$ & 0.2 & $-0.1,0.6$ & 0.0 & $0.0,0.0$ \\
\hline Hypothyroidism & 9.4 & $6.9,11.9$ & 18.3 & $11.7,24.9$ \\
\hline Osteopenia & 5.3 & $3.4,7.3$ & 0.0 & $0.0,0.0$ \\
\hline Nutritional assessment & 0.0 & $0.0,0.0$ & 17.6 & $11.0,24.1$ \\
\hline Nephrocalcinosis & 2.2 & $0.8,3.4$ & 11.5 & $5.9,16.9\left({ }^{*}\right)$ \\
\hline Renal tabular acidosis & 0.0 & $0.0,0.0$ & 2.3 & $-0.3,4.9$ \\
\hline Anemia & 19.6 & $16.2,23.1$ & 3.1 & $0.1,5.9\left(^{*}\right)$ \\
\hline $\begin{array}{l}\text { Developmental } \\
\text { dislocation of hip }\end{array}$ & 0.8 & $0.0,1.6$ & 0.0 & $0.0,0.0$ \\
\hline Oral health assessment & 0.0 & $0.0,0.0$ & 0 & $0.0,0.0$ \\
\hline Autism & 0.0 & $0.0,0.0$ & 0 & $0.0,0.0$ \\
\hline Child abuse & 0.0 & $0.0,0.0$ & 0 & $0.0,0.0$ \\
\hline Sleep disorders & 19.3 & $15.8,22.7$ & 9.2 & $4.2,14.1\left(^{*}\right)$ \\
\hline $\begin{array}{l}\text { Intraventricular } \\
\text { hemorrhage }\end{array}$ & 0.0 & $0.0,0.0$ & 0.8 & $-0.1,2.3$ \\
\hline Retinopathy & 2.8 & $1.3,4.2$ & 0.8 & $-0.1,2.3$ \\
\hline $\begin{array}{l}\text { Neurodevelopmental } \\
\text { assessment }\end{array}$ & 8.3 & $5.9,10.7$ & 0.0 & $0.0,0.0$ \\
\hline Auditory assessment & 1.4 & $0.4,2.4$ & 0.0 & $0.0,0.0$ \\
\hline
\end{tabular}

$\left({ }^{*}\right)$ The difference between proportions is statistically significant.

(i) coordinate the follow-up care with family;

(ii) provide the family with full package of the follow-up care (i.e., time table for clinical visits and instruction for various conditions and situations);

(iii) organize the timetable of clinical visits at regular basis;

(iv) arrange instruction and training sessions for family;

(v) enter the relevant data in the program online software;

(vi) prepare regular reports of the follow-up program.

(b) Access to some paramedical services has to be organized/arranged for those infants needing these services after discharge. Some of those services include occupational therapy, physiotherapy, speech therapy, clinical nutrition services, and psychology and psychotherapy facilities. Some families may also need financial aids to access those services.

(c) A major attention should be made for recall and follow-up of those high risk infants living in the villages far from the program hospital. They may need several calls to come for follow-up care. The program nurse/midwife may also need to be in close contact with the local family doctor to organize the regular follow-up visit for those infants.

One of our main limitations in the implementation of this follow-up program was improper infrastructure and insufficient capacity of online data handling in the country. If a program is to be implemented across the country, the online communication of the data between states, hospitals, and main office in the ministry of health has to be set up/administered properly.

As a conclusion, a follow-up care program for a minimum of six months after discharge from maternity hospitals may help to avoid adverse and life threatening consequences in high risk infants.

\section{Conflict of Interests}

The authors declare that there is no conflict of interests regarding the publication of this paper. 


\section{Acknowledgments}

The authors wish to thank United Nations Children Fund (UNICEF) in Iran for financial support of this study (no. 43147745). The authors also thank all the families and staff in Alzahra and Taleqani Hospitals for participating in the study.

\section{References}

[1] http://urlm.co/www.thebarkertheory.org.

[2] B. E. Stephens, R. Tucker, and B. R. Vohr, "Special health care needs of infants born at the limits of viability," Pediatrics, vol. 125, no. 6, pp. 1152-1158, 2010.

[3] S. M. Schulzke, G. C. Deshpande, and S. K. Patole, "Neurodevelopmental outcomes of very low-birth-weight infants with necrotizing enterocolitis: a systematic review of observational studies," Archives of Pediatrics and Adolescent Medicine, vol. 161, no. 6, pp. 583-590, 2007.

[4] D. J. Gunn, D. W. Cartwright, and G. A. Gole, "Incidence of retinopathy of prematurity in extremely premature infants over an 18-year period," Clinical \& Experimental Ophthalmology, vol. 40, no. 1, pp. 93-99, 2012.

[5] E. J. Short, N. K. Klein, B. A. Lewis et al., "Cognitive and academic consequences of bronchopulmonary dysplasia and very low birth weight: 8 -year-old outcomes," Pediatrics, vol. 112, no. 5, article e359, 2003.

[6] T. M. O'Shea and L. W. Doyle, "Perinatal glucocorticoid therapy and neurodevelopmental outcome: an epidemiologic perspective," Seminars in Neonatology, vol. 6, no. 4, pp. 293-307, 2001.

[7] American Academy of Pediatrics Committee on Fetus and Newborn, "Postnatal corticosteroids to treat or prevent chronic lung disease in preterm infants," Pediatrics, vol. 109, no. 2, pp. 330-338, 2002.

[8] S.-F. Jeng, C.-H. Hsu, P.-N. Tsao et al., "Bronchopulmonary dysplasia predicts adverse developmental and clinical outcomes in very-low-birthweight infants," Developmental Medicine \& Child Neurology, vol. 50, no. 1, pp. 51-57, 2008.

[9] A. Davis, S. Hintz, K. Van Meurs et al., "Eunice Kennedy Shriver National Institute of Child Health and Human Development Neonatal Research Network. Seizures in extremely low birth weight infants are associated with adverse outcomes," Journal of Pediatrics, vol. 157, pp. 720-725, 2010.

[10] A. Laptook, J. Tyson, S. Shankaran et al., "Elevated temperature after hypoxic-ischemic encephalopathy: risk factor for adverse outcomes," Pediatrics, vol. 122, no. 3, pp. 491-499, 2008.

[11] K. Lally and W. Engle, "Post discharge follow-up of infants with congenital diaphragmatic hernia," Pediatrics, vol. 121, pp. 627$632,2008$.

[12] American Academy of Pediatrics and Committee on Fetus and Newborn, "Hospital discharge of the high-risk neonate," Pediatrics, vol. 102, pp. 411-417, 1998.

[13] E. Waitzer, S. P. Riley, T. Perreault, and M. I. Shevell, "Neurologic outcome at school entry for newborns treated with extracorporeal membrane oxygenation for noncardiac indications," Journal of Child Neurology, vol. 24, no. 7, pp. 801-806, 2009.

[14] A. Amigoni, A. Pettenazzo, P. Biban et al., "Neurologic outcome in children after extracorporeal membrane oxygenation: prognostic value of diagnostic tests," Pediatric Neurology, vol. 32, no. 3, pp. 173-179, 2005.

[15] A. C. Jaffe, "Failure to thrive: current clinical concepts," Pediatrics in Review, vol. 32, no. 3, pp. 100-108, 2011.
[16] S. S. Corbett and R. F. Drewett, "To what extent is failure to thrive in infancy associated with poorer cognitive development? A review and meta-analysis," Journal of Child Psychology and Psychiatry, vol. 45, no. 3, pp. 641-654, 2004.

[17] L.-Y. Wang, H.-J. Luo, W.-S. Hsieh et al., "Severity of bronchopulmonary dysplasia and increased risk of feeding desaturation and growth delay in very low birth weight preterm infants," Pediatric Pulmonology, vol. 45, no. 2, pp. 165-173, 2010.

[18] J. K. Chye and P. H. Gray, "Rehospitalization and growth of infants with bronchopulmonary dysplasia: a matched control study," Journal of Paediatrics and Child Health, vol. 31, no. 2, pp. 105-111, 1995.

[19] M. Heidarzadeh, B. Jodiery, K. Mirnia et al., "Creating the action model for high risk infant follow up program in Iran," Iranian Journal of Public Health, vol. 42, no. 11, pp. 1309-1315, 2013.

[20] http://www.uichildrens.org/childrens-content.aspx?id=233999.

[21] https://www.ccshrif.org.

[22] A. R. Synnes, F. Lefebvre, and H. A. Cake, "Current status of neonatal follow-up in Canada," Paediatrics and Child Health, vol. 11, no. 5, pp. 271-274, 2006.

[23] V. S. Kuppala, M. Tabangin, B. Haberman, J. Steichen, and K. Yolton, "Current state of high-risk infant follow-up care in the United States: results of a national survey of academic follow-up programs," Journal of Perinatology, vol. 32, no. 4, pp. 293-298, 2012.

[24] http://www.canadianneonatalnetwork.org/portal.

[25] http://www.dhs.state.il.us/page.aspx?item $=32857$.

[26] G. J. Escobar, R. H. Clark, and J. D. Greene, "Short-term outcomes of infants born at 35 and 36 weeks gestation: we need to ask more questions," Seminars in Perinatology, vol. 30, no. 1, pp. 28-33, 2006.

[27] M. Adams, C. Borradori-Tolsa, M. Bickle-Graz et al., "Followup assessment of high-risk newborns in Switzerland," Paediatrica, vol. 25, no. 5, pp. 8-10, 2014.

[28] L. J. Schlapbach, M. Adams, E. Proietti et al., "The Swiss Neonatal Network and Follow-up Group. Outcome at two years of age in a Swiss national cohort of extremely preterm infants born between 2000 and 2008," BMC Pediatrics, vol. 12, article 198, 2012. 


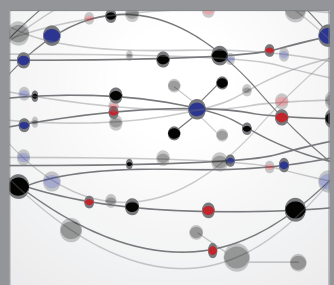

The Scientific World Journal
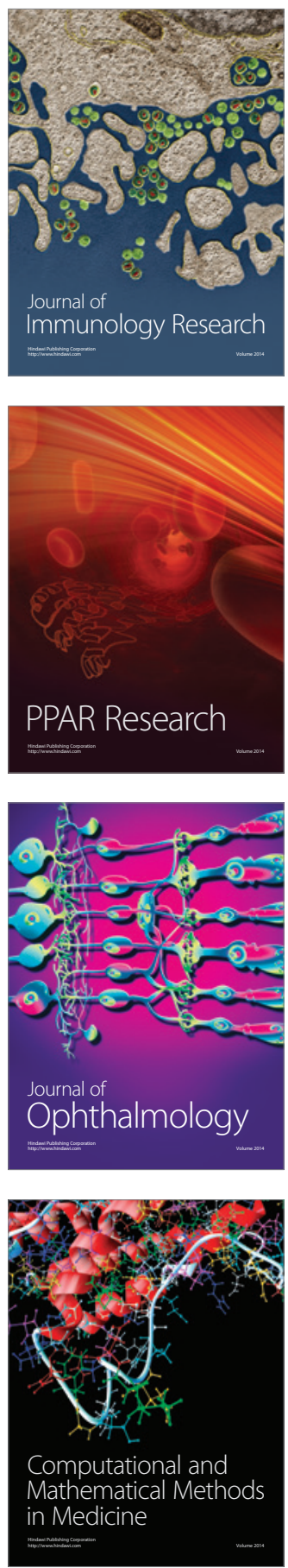

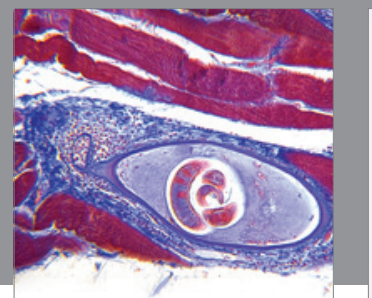

Gastroenterology

Research and Practice
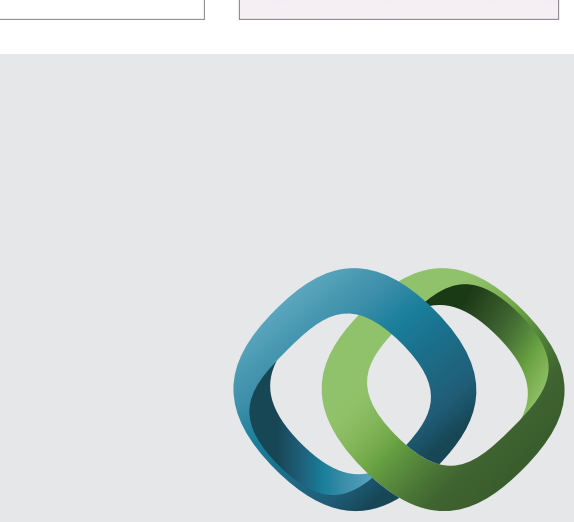

\section{Hindawi}

Submit your manuscripts at

http://www.hindawi.com
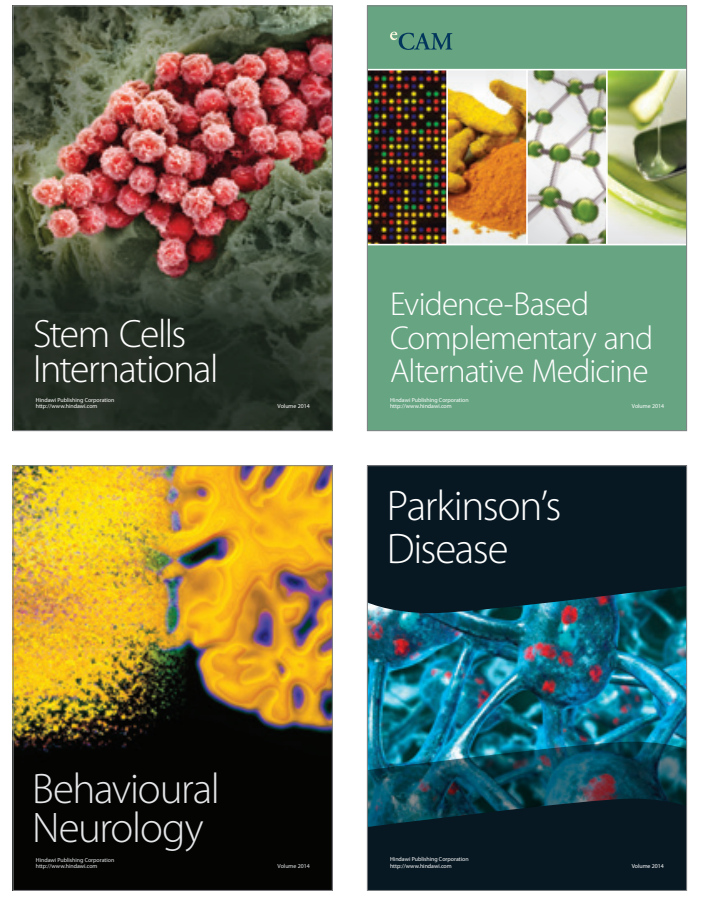
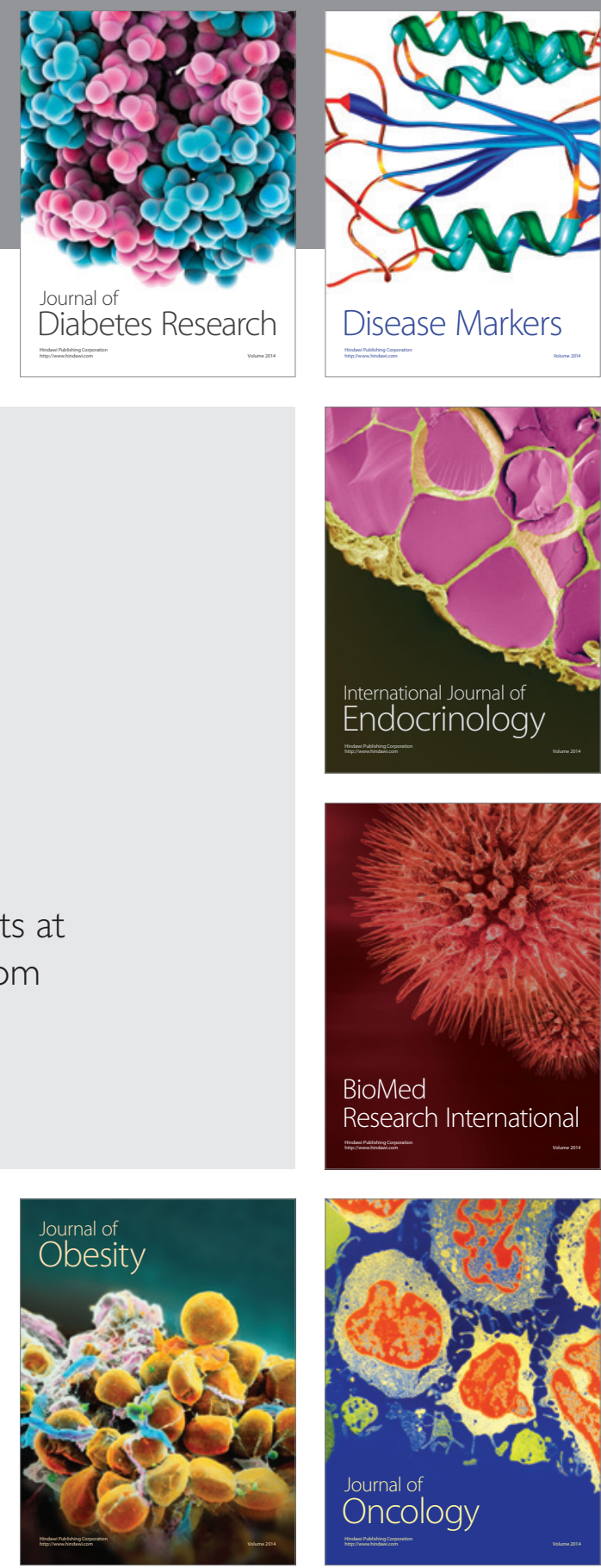

Disease Markers
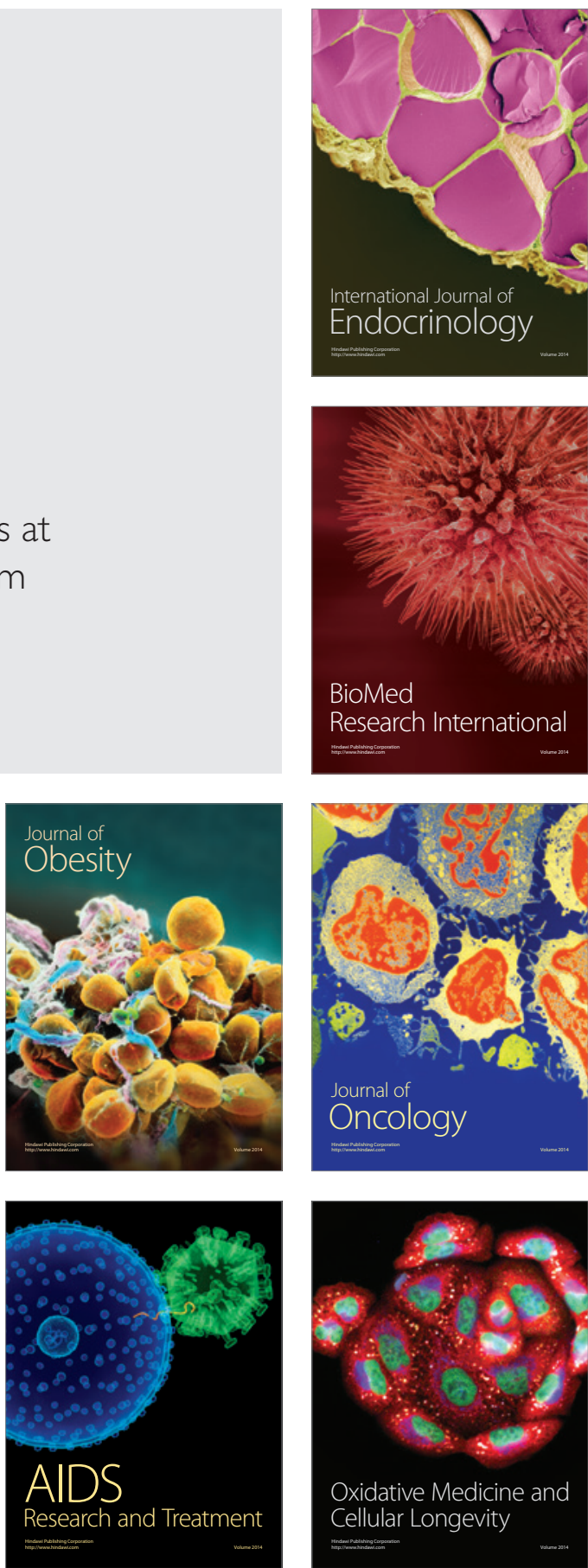